\title{
Tafeln
}

\section{Liste der gegen die Isaurier gerichteten Militäraktionen sowie der isaurischen Aufstände und Raubzüge}

\begin{tabular}{|c|c|c|}
\hline Jahr & Art des Aufstands / Raubzugs & Quelle \\
\hline 322 v. Chr. & Strafaktion des Perdikkas gegen Isaura & Diod. XVIII 22 \\
\hline $77-75$ v. Chr. & $\begin{array}{l}\text { Militäraktion unter P. Servilius Vatia } \\
\text { (Isauricus) gegen die Isaurier }\end{array}$ & $\begin{array}{l}\text { Amm. XIV 8, 4; App. Mithr. 93; } \\
\text { Cic. leg. agr. I 5. II 50 (früheste } \\
\text { Quelle); Cic. Verr. II 1, 21; II 3, } \\
\text { 211; II 4, 22; II 5, 79; III 91, } \\
\text { 211; Eutr. VI 3; Fest. Brev. XII } \\
\text { 3; Flor. epit. I 41; Frontin. strat. } \\
\text { III 7,1; Liv. per. 90. 93; Oros. V } \\
\text { 23; Sall. hist. frg. I 127-132; II } \\
\text { 81-87. III 1; Strab. XII 6,2; XIV } \\
\text { 5, 5; Suet. Iulius 3; Vell. II 39; } \\
\text { CIL I 2, 741. 766 a-S; } \\
\text { AE (1907) 204; AE (1977) 17; } \\
\text { HALL (1973) =AE (1977) 816. } \\
\text { (1984) 45. (1994) 567 }\end{array}$ \\
\hline 6 n. Chr. & $\begin{array}{l}\text { Aufstand und Unterdrückung durch den } \\
\text { Legaten M. Plautius Silvanus }\end{array}$ & Dio $55,28,3$ \\
\hline 17 & $\begin{array}{l}\text { Isaurische Söldner unterstützen den } \\
\text { rebellischen P. Cnaeus Piso }\end{array}$ & Tac. ann. II 80 \\
\hline 36 & $\begin{array}{l}\text { Aufstand der Kieten gegen eine Steuer- } \\
\text { erhebung des Archelaus, Nieder- } \\
\text { schlagung durch Legaten M. Trebellius }\end{array}$ & Tac. ann. VI 41 \\
\hline $43-48$ & $\begin{array}{l}\text { Aktion des Q. Veranius gegen } \\
\text { isaurische Festungen }\end{array}$ & $A \dot{E}(1953) 251$ \\
\hline 52 & $\begin{array}{l}\text { Aufstand und Belagerung von } \\
\text { Anemurium, beendet durch den } \\
\text { Praefecten Curtius Severus und den } \\
\text { Klientelkönig Antiochos v. Kommagene }\end{array}$ & Tac. ann. XII 55 \\
\hline \multicolumn{3}{|c|}{ [Hohe Kaiserzeit: Keine Konflikte bezeugt] } \\
\hline 278 & $\begin{array}{l}\text { Belagerung des in Cremna verschanzten } \\
\text { Palfuerius qui et Lydius durch den } \\
\text { praeses Terentius Marcianus }\end{array}$ & $\begin{array}{l}\text { SHA Prob. 16, } 4 \text {; Zos. I } 69,2 \mathrm{ff} ; \\
\text { Inscriptions of Central Pisidia } \\
47 \mathrm{ff} ., \text { Nr. } 15\end{array}$ \\
\hline 343 & $\begin{array}{l}\text { der vicarius Asiae Scylacius vertreibt } \\
\text { isaurische Räuber }\end{array}$ & Himerios or. 25, Z. $88-98$ \\
\hline 354 & $\begin{array}{l}\text { großer Aufstand nach Hinrichtung } \\
\text { gefangener Isaurier in Iconium }\end{array}$ & Amm. XIV 2; Mir. 5 \\
\hline $354(?)$ & $\begin{array}{l}\text { Isaurische Banditen ermorden Eltern } \\
\text { eines Freundes des Libanius }\end{array}$ & Lib.ep. 426 \\
\hline
\end{tabular}




\begin{tabular}{|c|c|c|}
\hline 359 & $\begin{array}{l}\text { Raubzug, bekämpft von Bassidius } \\
\text { Lauricius }\end{array}$ & Amm. XIX 13 \\
\hline $367-368$ & $\begin{array}{l}\text { Raubzüge, Untergang des Musonius, } \\
\text { Friedensvertrag in Germanicopolis }\end{array}$ & Amm. XXVII 9, 6 ff. \\
\hline $375-376$ & weiterer Aufstand & Hinweise in Zos. IV 20; Mir. 13 \\
\hline $397-408$ & $\begin{array}{l}\text { Ausgedehnte Raubzïge nach } \\
\text { Pamphylien und bis nach Palästina, } \\
\text { Bekämpfung durch den Goten Fravitta } \\
\text { und durch Arbazacius }\end{array}$ & $\begin{array}{l}\text { CTh IX 35, 7; Eun. frg. } 69,2.71 \text {, } \\
\text { 1. 4; Hier. ep. } 77,8.114 ; \text { Joh. } \\
\text { Chrysost. ep. ad Olympiadem VI } \\
\text { 1. IX 2. 3. 4. XVI 1. XVII 1; } \\
\text { ep. 52. 57. 61. 68f. } 72.108 f .114 . \\
\text { 120f. 127. 131. 135f. 142. } 146 \\
\text { (PG 52); Hier. ep. 114, 1; } \\
\text { Marc. Com. s.a. 405; Pallad. } \\
\text { Dial. 11; Philostorg. h.e. XI 8; } \\
\text { Soz. h.e. VIII 25, 1; V. Simeonis } \\
\text { Stylitae p. 83f.; Zos. V 20f., 25. }\end{array}$ \\
\hline 441 & Raubzüge & Marc. Com. s.a. 441 \\
\hline 447 & Raubzüge & Prisc. frg. 10, Z. 13 \\
\hline ca. 450 & $\begin{array}{l}\text { (wohl nur geplante) Kampagne gegen } \\
\text { den ersten Zeno in dessen Heimat }\end{array}$ & Joh. Ant. frg. 199 \\
\hline $467(?)$ & Plünderung von Rhodos & Joh. Ant. frg. 206,1 \\
\hline 469 & Aufstand des Indacus & Joh. Ant. frg. 206,2 \\
\hline $479 / 480$ & $\begin{array}{l}\text { Eroberung von Korykos und Elaiussa } \\
\text { Sebaste während der Marcian-Revolte } \\
\text { gegen Kaiser Zeno. }\end{array}$ & Joh. Ant. frg. 211,4 \\
\hline 492 & Isaurierkrieg des Kaisers Anastasius & $\begin{array}{l}\text { Theoph. AM 5984f., Euagr. h.e. } \\
\text { III 29. 35; Mal. XVI p. 320; } \\
\text { Marc. Com. s. a. 492; Joh. Ant. } \\
\text { frg. 100, 214b; Jord. Rom. 354; } \\
\text { Jos. Styl. 23; Theod. Lect. II 9; } \\
\text { Zach. Rhet. h.e. VII 1. }\end{array}$ \\
\hline
\end{tabular}

